\title{
BRIEF
}

\section{Communication Apprehension Among Health Students}

\author{
Dyego Carlos Souza Anacleto de Araújo, Kérilin Stancine Santos Rocha, Sabrina Cerqueira-Santos, Pedro \\ Wlisses dos Santos Menezes, Sylmara Nayara Pereira dos Santos, Willian Melo dos Santos, André Faro, PhD, \\ Alessandra Rezende Mesquita, PhD, Divaldo Pereira de Lyra Jr, PhD
}

Federal University of Sergipe, São Cristóvão, Sergipe, Brazil

Corresponding Author: Divaldo Pereira de Lyra Jr, Federal University of Sergipe, Department of Pharmacy, Cidade Universitária "Prof. José Aloísio Campos", Jardim Rosa Elze, São Cristóvão, CEP: 49100-000, Brazil. Tel: +55 793194 6319. Email: lepfs.ufs@gmail.com

Submitted February 16, 2021; accepted June 25, 2021; ePublished July 2021

Objective. To determine the levels of communication apprehension (CA) experienced by health students and compare them according to sex, age range, course, and academic year.

Method. A cross-sectional study was conducted at a Brazilian university from December 2019 to May 2020 with dentistry, pharmacy, medicine, and nursing students, recruited by convenience sampling. The students were invited to answer a survey consisting of two sections: general characteristic and the Personal Report of Communication Apprehension (PRCA-24). Univariate and bivariate analyses were conducted.

Results. A total of 644 health students answered the survey, of whom $25.5 \%$ were classified as having high communication apprehension. Male participants had significantly lower PRCA-24 scores than females. No significant differences were found between PRCA-24 scores by age category or academic year. Medical students had significantly lower mean PRCA-24 scores than pharmacy students.

Conclusion. The prevalence of high CA was high and apparently remained stable over time. The highest scores for CA were obtained by women and pharmacy students. Health educators should consider the effects of communication apprehension and use adequate interventions during communication skills training.

Keywords: communication skills, anxiety, fear

\section{INTRODUCTION}

Over the last decades, there has been a substantial increase in interventions and frameworks concerned with the development of health care professionals' individual capacity to communicate effectively with patients and other professionals. ${ }^{1-5}$ Despite the importance of communication skills, relatively little is known about the obstacles that health students face when attempting to improve their ability to communicate. Communications studies have recognized that one of the major obstacles to communication skills development may be the communication apprehension (CA). ${ }^{6-8}$ This phenomenon has been defined by McCroskey as "an individual's level of fear and anxiety associated with either real or anticipated communication with another person or persons", and it is the most researched constructs in the field of human communication for over five decades. ${ }^{9,10}$

Firstly, it is important to note that CA and communication skills are two distinct dimensions of the communication process. CA refers to what the individual feels when communicating, rather than how communicates. An individual can have excellent communication skills, but still have high CA and feels high degree of anxiety and tension in communication situations. ${ }^{9-11}$ According to McCroskey (1982) CA may be viewed on a continuum with four points: i) situational CA, a transitory orientation toward communication with a given person or group of people; ii) person-Group CA, a relatively enduring orientation toward communication with a given person or group of people; iii) generalized-context CA, a relatively enduring, personality type orientation toward communication in a given type of context; iv) trait-CA, a personality-type orientation toward a given mode of communication across a wide variety of contexts. ${ }^{12}$

The literature has shown that individuals with high CA are less able to communicate effectively because this apprehension amplifies the predisposition to avoid communicating with others. ${ }^{12-14}$ Based on these previous research, it is possible that health care professionals with high CA are more likely to avoid communicating with patients or other professionals, and might not provide adequate patient education. ${ }^{15,16}$ Researchers have advanced our understanding of the characteristics related to CA and their pedagogical and potential professional implications, especially among pharmacy students in the United States. ${ }^{15,17-21}$ LaRochelle and Karpinski, for example, observed that CA may negatively affects pharmacy students' interprofessional socialization. ${ }^{15}$

In Brazil, communication is one of the five general competencies and skills advocated by the National Curriculum Guidelines for health professions education. Besides that, the formal teaching of these skills is less frequent when compared to other countries, especially in pharmaceutical education. ${ }^{22-25}$ Araujo et al. identified gaps in the 
curricula of undergraduate courses in pharmacy concerning the inclusion of the teaching of communication skills. ${ }^{22}$ The current National Curriculum Guidelines for Pharmacy state that pharmacists should be trained in three axes: health care provision, management, and technology/innovation. ${ }^{26}$ These pharmaceutical professional activities are in accordance with the guidelines published by World Health Organization and the International Pharmaceutical Federation, focused on family and community care; patient care; and organization and management of services, and professional and personal development for health care provision. ${ }^{26-28} \mathrm{CA}$ can be a potential barrier to the development of these competencies, where communication is indispensable.

Understanding this phenomenon among health students is the first step in discussing and implementing interventions to help them manage CA and reduce its impact on professional practice. We must explore how this phenomenon affects students of different health courses in other countries and cultures. The aims of this study were to: (a) determine the levels of trait-CA experienced by Brazilian health students and (b) compare levels of trait-CA according to sex, age range, course, and academic year.

\section{METHODS}

A cross-sectional study was conducted at the Federal University of Sergipe, Brazil, from December 2019 to May 2020. The population of the study was all current dentist, pharmacy, medical, and nursing students enrolled at the university. According to the Integrated Management System of Academic Activities, 1,332 students were found to be potentially eligible (337 Pharmacy students; 533 Medical students; 297 Nursing students; 165 Dental students). This number was used to estimate the sample size, using the Raosoft sample size calculator:

(http://www.raosoft.com/samplesize.html), confidence level of 99\%, a pre-determined margin of error of 5\%, and $20 \%$ of distribution for individuals with high CA. The calculated sample size was 323 . Students were recruited by convenience sampling.

Data were collected using a self-administered paper-based or online survey designed using Google Forms. In both cases, prior to participation, students received an explanatory statement outlining the purpose of the research, duration, and confidentiality of their data. In the case of paper-based surveys, trained researchers visited students during the class time of mandatory courses from December 2019 to March 2020. All researchers introduced the study to students using a standardized script to minimize potential biases. Only the online survey was administered in March 2020 to students in the last academic years who were in internships outside the university.

The survey consisted of two sections: general characteristics (sex, age, course, and academic year) and the Personal Report of Communication Apprehension (PRCA-24). PRCA-24 is a specific instrument that includes 24 statements to measure trait-like CA across four communication contexts: dyadic, meeting, public, and small groups. Respondents use a 5-point Likert-type scale to rate their level of agreement with each statement. Scores range from 24 to 120, with higher scores indicating higher levels of apprehension. High levels of CA were classified according to a score of $\geq 85$. This instrument was originally developed by McCroskey (1982) and was validated to BrazilianPortuguese, showing internal consistency, content, criterion, and construct validity. ${ }^{29}$

The data were analyzed using a combination of descriptive and comparative statistics using JASP (v. 0.12.2). Descriptive statistics were used to summarize the students' characteristics and PRCA-24 data. We assumed a normal distribution of data based on the skewness (-.132) and kurtosis (-.521) measures. T-test was used to compare PRCA-24 according to sex, and analysis of variance (ANOVA) was used to compare the differences by age range, course, and academic year. The hypothesis of homogeneity of variance was verified by the Levene test and, when rejected, the correction of Brown-Forsythe and the Post-Hoc Games-Howell test was used. Differences were considered significant when the $p$-value was $<.05$. The magnitude of effect was interpreted in accordance with Cohen's effect size classification. $^{30}$

This study was approved by the Ethics Committee of the Federal University of Sergipe (Protocol no. 3.588.162). Participation was voluntary and anonymous. Written informed consent was obtained from all participants.

\section{RESULTS}

Of 1,332 health students eligible for the study, 644 (48.4\%) took part in the survey. Of this sample, $61 \%$ ( $n$ $=393$ ) were female, and the ages (in years) were distributed across the following categories: $18-21(n=366 ; 56.8 \%)$, $22-25(n=201 ; 31.2 \%)$, and $>25(n=77 ; 5.8 \%)$. The majority were studying Pharmacy $(n=230 ; 35.7 \%)$, followed by Medicine $(n=209 ; 32.4 \%)$, Nursing $(n=130 ; 20.2 \%)$, and Dentistry $(n=75 ; 11.6 \%)$. The PRCA-24 scores for the health students ranged from 29 to 112 ; the general mean was $71.9 \pm 17.6$, and $25.5 \%$ of health students were classified as having high CA (Table 1).

The $t$-test results indicated that males had significantly lower scores than female students $(p<.001 ; d=-.339)$. ANOVA revealed no significant differences between PRCA-24 scores by age category $\left(F_{(2,641)}=1.009, p=.365\right)$ or academic year $\left(F_{(2,641)}=1.979, p=.139\right)$. There were significant differences between the courses in total PRCA-24 scores (Brown-Forsythe $F_{(3,512)}=3.463, p=.016, \eta^{2}=.02$ ). Post hoc tests revealed that medical students had significantly lower mean PRCA-24 scores than pharmacy students $(p=.014)$ (Table 2). 


\section{DISCUSSION}

This cross-sectional study represents an initial attempt to investigate CA among Brazilian health students. Our results suggest that approximately one in four students may have high CA. This high prevalence becomes even more important when we consider that no difference in CA levels was identified by age or academic year. Therefore, students with high CA will likely be professionals with high CA and may have interpersonal problems during professional practice. ${ }^{16}$ Some studies also indicate that apprehension levels are stable over the years and that a student's academic year has no significant effect on apprehension level. ${ }^{16,18,31}$ This points to a potential deficiency in the communication levels for health students and the need to review current models of skills development.

We also observed that female students scored significantly higher than males on CA scores. Existing published evidence has demonstrated that there are slight gender differences in total PRCA-24 scores. ${ }^{32-34}$ These differences are often ascribed to the cultural biases resulting from social roles and psychological stereotypes of the genders. ${ }^{35,36}$ Some researchers argue that in a patriarchal society, women are silenced and so they develop fear and anxiety toward expressing themselves. ${ }^{37-39}$ This difference presented a small effect size, but it is important to discuss this finding because women comprise two-thirds of the global health workforce and we do not know how CA affects their practice. ${ }^{40}$

Significant differences were observed between the CA scores of medical and pharmacy students. Despite the small effect size, it is curious to note that, among all evaluated courses, pharmacy students had the highest scores of CA, while medical students had the lowest. According to the literature, individuals with high CA prefer occupations that require little oral communication. ${ }^{4-43}$ Unlike other health professionals, the expanded role of the pharmacist as a member of the health team in Brazil is a recent development and its stereotype is still related to bureaucratic aspects and the logistic aspect of drug production and distribution. Thus, it is possible that individuals with high CA chose to study pharmacy due to their perceived lack of patient involvement. As the public perception of "what the pharmacist does" changes, Pharmacy course may become less attractive to high-CA individuals. ${ }^{18,44,45}$ Until that occurs, developing and implementing effective interventions to manage CA is necessary to consolidate pharmacists' clinical roles.

Findings from this study can provide useful information to guide educators in understanding how to structure their curricula to improve communication skills and reduce CA. It is important that health professions education, especially pharmacy education, implement integrated and longitudinal communication training to reduce CA and, consequently, decrease the differences between males and females. Students with high CA, for example, may have satisfactory or unsatisfactory communication skills and this training program must consider that different students will need different types of interventions. Students with high CA and satisfactory communication skills usually only need interventions to reduce their level of CA. On the other hand, students with high CA and unsatisfactory communication skills will need two types of interventions: firstly, one to reduce their level of CA, and the other to improve communication skills. The most recommended teaching strategies for communication skills improvement have a high degree of exposure (such as simulations or role-playing), which may worsen the problem of students with high CA. ${ }^{46-48}$

Systematic desensitization (relaxation therapy, hierarchical approach) and cognitive restructuring have been used to reduce CA in pharmacy students. ${ }^{45,49}$ This intervention consists of identifying students with high CA, teaching them relaxation methods, and engaging them in role-playing sessions. It is important to point out that although desensitization training has potential benefit in decreasing CA, it is resource-intensive and may be difficult to implement in communication training. Rogers and King (2012) also reduced CA levels of pharmacy students using small-group practice sessions, case studies, and role-play, however we do not know the impact of these interventions on high CA students separately. ${ }^{19}$

Although this study revealed some insight on CA among health students, the study did have some limitations. First, the students who made up the sample were enrolled in only one school. Brazil is a country of continental dimensions with significant cultural differences. CA is also a cultural result, so the findings of this study cannot be generalized. Second, as this was a cross-sectional study, it was not able to assess the effects of age and academic year on apprehension levels. Third, we did not collect information about previous participation in communication courses, making it impossible to compare students who did not participate with students who did. We hope that these results will encourage the development and implementation of new interventions for CA reduction. Future studies should consider a longitudinal design to detect changes in the CA level over time and their relationship with student's confidence and selfefficacy. The implications of CA on the communication skills development of health students also should be investigated.

\section{CONCLUSION}

The prevalence of high CA was high, and it apparently remained stable over time, which provide a starting point for health educators to consider the CA as a problem. The highest scores were shown by women and pharmacy students. For health students without communication skills and low CA, training and practice will probably be appropriate. However, traditional training will not be sufficient for those with high CA. Educators should implement specific interventions to reduce or control CA during communication skills training, such as systematic desensitization.

\section{ACKNOWLEDGMENTS}


This research was supported by the Coordenação de Aperfeiçoamento de Pessoal de Nível Superior (CAPES).

\section{REFERENCES}

1. Bachmann C, Abramovitch H, Barbu CG, et al. A European consensus on learning objectives for a core communication curriculum in health care professions. Patient Educ Couns. 2013;93(1):18-26. doi:10.1016/j.pec.2012.10.016

2. Makoul G, Schofield T. Communication teaching and assessment in medical education: An international consensus statement. Patient Educ Couns. 1999;37(2):191-195. doi:10.1016/S0738-3991(99)00023-3

3. Kurtz SK, Silverman J, Benson J, Draper J. Marrying content and process in clinical method teaching: enhancing the Calgary-Cambridge guides. Acad Med. 2003;78(8):802-809.

4. Cömert M, Zill M, Christalle E, Dirmaier J, Härter M, Scholl I. Assessing Communication Skills of Medical Students in Objective Structured Clinical Examinations (OSCE)-A Systematic Review of Rating Scales. PloS One. 2016;11(3):e0152717. doi:10.1371/journal.pone.0152717

5. Liu X, Rohrer W, Luo A, Fang Z, He TH, Xie W. Doctor-patient communication skills training in mainland China: A systematic review of the literature. Patient Educ Couns. 2015;98(1):3-14. doi:10.1016/j.pec.2014.09.012

6. Joyce J, Hassall T, Montaño JLA, Anes JAD. Communication apprehension and maths anxiety as barriers to communication and numeracy skills development in accounting and business education. Educ Train. 2006;48(6):454-464. doi:10.1108/00400910610692967

7. Hassall T, Arquero JL, Joyce J, Gonzalez JM. Communication apprehension and communication self-efficacy in accounting students. Asian Rev Account. 2013;21(2):160-175. doi:10.1108/ARA-03-2013-0017

8. Arquero JL, Hassall T, Joyce J, Donoso JA. Accounting students and communication apprehension: A study of Spanish and UK students. Eur Account Rev. 2007;16(2):299-322. doi:10.1080/09638180701391337

9. McCroskey JC. Communication apprehension: What have we learned in the last four decades. Hum Commun. 2009;12(2):157-171.

10. Beatty MJ, Pascual-Ferrá P. Communication Apprehension. In: The International Encyclopedia of Interpersonal Communication. Wiley; 2015:1-9. doi:10.1002/9781118540190.wbeic099

11. Sawyer CR, Behnke RR. Communication state anxiety. In: Daly JA, McCroskey JC, Ayres, J., Hopf T, AyresSonandre DM, Wongprasert TK, eds. Avoiding Communication: Shyness, Reticence, and Communication Apprehension. Cresskill, NJ: Hampton Press; 2009:85-96.

12. Mccroskey JC. Oral Communication Apprehension: A Reconceptualization. Annals of the International Communication Association. 1982;6(1):136-170. doi:10.1080/23808985.1982.11678497

13. Clay J, Crookes PA. Implications of transplantation surgery for theatre nurses:2. Br J Nurs. 1996;5(8):467468,470. doi:10.12968/bjon.1996.5.8.467

14. Murphy M, Weber K. Confirmation of the Ability of the Personal Report of Communication Apprehension-24 (PRCA-24) to Predict Behavioral Indicators of Social Interaction. Commun Res Rep. 2019;36(5):393-403. doi:10.1080/08824096.2019.1683527

15. Larochelle JM, Karpinski AC. Racial differences in communication apprehension and interprofessional socialization in fourth-year doctor of pharmacy students. Am J Pharm Educ. 2016;80(1). doi:10.5688/ajpe8018

16. Emory J, Kippenbrock T, Lee P, Miller MT, Reimers J. Communication apprehension and willingness to listen in nursing education. J Prof Nurs. 2017;34(4):284-288. doi:10.1016/j.profnurs.2017.09.004

17. Berger BA, Baldwin HJ, McCroskey JC, Richmond VP. Communication Apprehension in Pharmacy Students: A National Study. Am J Pharm Educ. 1983;47(2):95-101.

18. Baldwin HJ, McCroskey JC, Knutson TJ. Communication Apprehension in the Pharmacy Student. Am J Pharm Educ. 1979;43(2):91-93.

19. Rogers ER, King SR. The influence of a patient-counseling course on the communication apprehension, outcome expectations, and self-efficacy of first-year pharmacy students. Am J Pharm Educ. 2012;76(8).

doi:10.5688/ajpe768152

20. Hastings JK, West DS. Comparison of outcomes between two laboratory techniques in a pharmacy communications course. Am J Pharm Educ. 2003;67(4):1-7. doi:10.5688/aj6704101

21. Rust C, Gentry WM, Ford H. Assessment of the effect of communication skills training on communication apprehension in first year pharmacy students - A two-year study. Curr Pharm Teach Learn. 2020;12(2):142146. doi:10.1016/j.cptl.2019.11.007

22. Araújo DC, Santos JS, Barros IM, Cavaco AM, Mesquita AR, Lyra DP. Communication skills in brazilian pharmaceutical education: A documentary analysis. Pharm Pract. 2019;17(1). doi:10.18549/PharmPract.2019.1.1395

23. Araújo DCSA de, Menezes PW dos S, Cavaco AM das N, Mesquita AR, Lyra Júnior DP de. Instrumentos para avaliação de habilidades de comunicação no cuidado em saúde no Brasil: uma revisão de escopo. Interface (Botucatu). 2020;24:e200030. doi:10.1590/interface.200030 
24. Liberali R, Novack D, Duke P, Grosseman S. Communication skills teaching in Brazilian medical schools: What lessons can be learned? Patient Educ Couns. 2018;101(8):1496-1499. doi:10.1016/J.PEC.2017.12.021

25. Araújo DCSA, Santos JS, Da Cunha Barros IM, Cavaco AMN, Mesquita AR, De Lyra DP. Sign language in Brazilian pharmacy education. Am J Pharm Educ. 2019;83(8):1676-1680. doi:10.5688/ajpe7239

26. Brasil. Institui as Diretrizes Curriculares Nacionais Do Curso de Graduação Em Farmácia e Dá Outras Providências. Diário Oficial da União; 2017:Seção 1.

27. World Health Organization. The Role of the Pharmacist in the Health Care System: Preparing the Future Pharmacist: Curricular Development.; 1997.

28. International Pharmaceutical Federation. A Global Competency Framework for Services Provided by Pharmacy Workforce.; 2012.

29. de Araújo DCSA, Pereira SN, dos Santos WM, et al. Brazilian version of the Personal Report of Communication Apprehension: Cross-cultural adaptation and psychometric evaluation among healthcare students. Wang M-C, ed. PLoS One. 2021;16(2):e0246075. doi:10.1371/journal.pone.0246075

30. Cohen J. Things I have learned (so far). Am Psychol. 1990;45(12):1304-1312. doi:10.1037/10109-028

31. Aly IM, Islam M. Audit of accounting program on oral communications apprehension: A comparative study among accounting students. Manag Audit J. 2003;18(9):751-760. doi:10.1108/02686900310500514

32. Hassall T, Joyce J, Ottewill R, Arquero J, Donoso J. Communication apprehension in UK and Spanish business and accounting students. Educ Train. 2000;42(2):93-100. doi:10.1108/EUM0000000005351

33. Peng SY, Ali MSBS. Communication Apprehension: A comparison between english majors and non-majors in China. Int J Appl Linguistics English Lit. 2015;4(6):190-195. doi:10.7575/aiac.ijalel.v.4n.6p.190

34. Loureiro M, Loureiro N, Silva R. Differences of Gender in Oral and Written Communication Apprehension of University Students. Educ Sci. 2020;10(12):379. doi:10.3390/educsci10120379

35. Greenblatt L, Hasenauer JE, Freimuth VS. Psychological sex type and androgyny in the study of communication variables: Self-disclosure and communication apprehension. Hum Commun Res. 2006;6:117-129.

36. Allen J, O'Mara J, Andriste G. Communication apprehension in bilingual nonnative US residents-part II: Gender, second language experience and communication apprehension in functional contexts. World Communication. 1986;15(1):14.

37. Lakoff R. Language and Woman's Place. Harper \& Row; 1975.

38. Key MR. Male/Female Language. Scarecrow Press; 1975.

39. Thorne B, Henley N. Difference and dominance: an overview of language, gender and society. In: Thorne B, Henley N, eds. Language and Sex: Difference and Dominance. Newbury House; 1975.

40. Magar V, Gerecke M, Dhillon I, Campbell J. Women's contribution to sustainable development through work in health: Using a gender lens to advance a transformative 2030 agenda. In: World Health Organization, ed. Health Employment and Economic Growth: An Evidence Base. ; 2016.

41. Daly JA, Mccroskey JC. Occupational Desirability and Choice as a Function of Communication Apprehension. $J$ Couns Psychol. 1975;22(4):309-313.

42. McCroskey JC, Daly JA, Sorensen G. Pernonality correlates of Communication Apprehension: a research note. Hum Commun Res. 1976;2(4):376-380. doi:10.1111/j.1468-2958.1976.tb00498.x

43. Arquero JL, Fernández-Polvillo C, Valladares-García D. Communication apprehension and students' educational choices: an exploratory analysis of Spanish secondary education students. Education and Training. 2017;59(9):946-956. doi:10.1108/ET-04-2017-0049

44. Bellone M, Cottencin O, Rigot JM, Goudemand M. Study on psychiatric disorders and defensive process assessed by the "defense style questionnaire" in sterile males SAMPLE consulting in andrology. L'Encephale. 2005;31:414-425. doi:10.1016/s0013-7006(05)82403-0

45. Berger BA, Baldwin HJ, Mccroskey JC, Richmond VP. Implementation of a Systematic Desensitization Program and Classroom Instruction to Reduce Communication Apprehension in Pharmacy Students. Am J Pharm Educ. 1982;46:227-234.

46. Wallman A, Vaudan C, Kälvemark Sporrong S. Communications training in pharmacy education, 1995-2010. Am J Pharm Educ. 2013;77(2). doi:10.5688/ajpe77236

47. Adrian JAL, Zeszotarski P, Ma C. Developing pharmacy student communication skills through role-playing and active learning. Am J Pharm Educ. 2015;79(3). doi:10.5688/ajpe79344

48. Lupu AM, Stewart AL, O’Neil C. Comparison of active-learning strategies for motivational interviewing skills, knowledge, and confidence in first-year pharmacy students. Am J Pharm Educ. 2012;76(2):1-7. doi:10.5688/ajpe76228

49. Berger BA, McCroskey JC. Reducing Communication Apprehension in Pharmacy Students. Am J Pharm Educ. 1982;46(2):132-136. 
Table 1. Descriptive Statistic According to Course

\begin{tabular}{llllll}
\hline Statistic & $\begin{array}{l}\text { Dentistry } \\
(\mathbf{n = 7 5})\end{array}$ & $\begin{array}{l}\text { Medicine } \\
(\mathbf{n = 2 0 9})\end{array}$ & $\begin{array}{l}\text { Nursing } \\
(\mathbf{n = 1 3 0})\end{array}$ & $\begin{array}{l}\text { Pharmacy } \\
(\mathbf{n = 2 3 0})\end{array}$ \\
\hline Female, n (\%) & $50(66.7)$ & $86(41.2)$ & $94(72.3)$ & $163(70.9)$ & $\begin{array}{l}\text { Total } \\
(\mathbf{n}=\mathbf{6 4 4})\end{array}$ \\
Age, Mean (SD) & $21.8(2.8)$ & $22.0(3.9)$ & $21.9(3.6)$ & $21.7(3.9)$ & $21.9(3.8)$ \\
PRCA-24, Mean (SD) & $72.5(15.9)$ & $69(19.4)$ & $71.9(16.9)$ & $74.3(16.6)$ & $71.9(17.6)$ \\
PRCA-24, IQ25-75 & $60-86$ & $55-83$ & $61-82$ & $64-86$ & $59-85$ \\
PRCA-24, Min-Max & $45-107$ & $29-112$ & $35-112$ & $31-111$ & $29-112$ \\
High CA, $n(\%)$ & $19(25.3)$ & $54(25.8)$ & $27(20.8)$ & $64(27.8)$ & $164(25.5)$ \\
\hline
\end{tabular}

PRCA = Personal Report of Communication Apprehension; IQ 25-75: range interquartile

Table 2. Group Comparation Scores of Personal Report of Communication Apprehension among Brazilian Health Students

$\begin{array}{llll}\text { Groups } & \text { n (\%) } & \text { Mean (Standard Deviation) } & \text { Statistics values }\end{array}$

Sex

Male

$251 \quad 68.3(18.6)$

$74.2(16.7)$

$p<.001$

Female

393

$\mathrm{t}_{(642)}=-4.19$

Cohen's d $=-.339$

Age categories ${ }^{1}$

18-21 years

22-25 years

366

201

77

$1.0(17.7)$

$73.2(17.1)$

$>25$ years

75

209

130

230

$72.4(18.9)$

$p=.365$

$\mathrm{F}_{(2,641)}=1.009$

$\eta^{2}=.003$

\section{Course $^{2}$}

Dentistry

Medicine

Nursing

Pharmacy

217

241

168

Academic year

$1^{\text {st }}$ year

$2^{\text {nd }}$ and $3^{\text {rd }}$ year

$4^{\text {th }}$ and $5^{\text {th }}$ year

$72.5(15.9)$

$69.0(19.4)$

$71.9(16.9)$

$74.3(16.6)$

$$
\begin{aligned}
& p=.016 \\
& \mathrm{~F}_{(3,512)}=3.463 \\
& \eta^{2}=.015
\end{aligned}
$$

Levene test of homogeneity of variances indicated that PRCA-24 scores were homogeneously distributed $(p>.05)$

2The Levene test indicated that the PRCA-24 scores were not homogeneously distributed among different health students $(p<.05)$. Therefore,

ANOVA with Brown-Forsythe F was conducted. Significant post hoc Games-Howell indicates differences between Pharmacy and Medicine

Scores $(p=.014)$. 